\title{
An audit of medical presentations to an Emergency Department (ED) of patients aged 14-16 years. Are we following national guidelines?
}

\author{
Husnain Mahomed, Peter O’ Reilly, Abrar Haider, John Twomey, Anne-Marie Murphy
}

Department of Paediatrics, University Hospital Limerick, Limerick, Ireland

\section{INTRODUCTION}

In January 2017, a mandate outlined in the "National Model of Care for Paediatric \& Neonatology and Emergency Medicine" was issued in the Republic of Ireland dictating that all patients have their medical care overseen by Paediatricians up until the eve of their $16^{\text {th }}$ birthday. Prior to this, practice varied widely between the more than 20 institutions which oversee medical care of children throughout our nation. In our region, before 2017, medical patients over 14 at first presentation were seen by adult services. Through this mandate the Healthcare Service Executive (HSE) plans to standardise the level of care offered nationally and improve health outcomes for this patient cohort.

$\mathrm{Li}$ Z, et al (2018) most recently highlighted the lack of focus and investment into adolescent healthcare relative to the size of the estimated 1.8 billion global population. They concluded that only $1.6 \%$ of global funding is allocated to adolescent health despite making up one-fourth of the global population. Thus this new focus by the HSE on adolescent healthcare has been welcomed by Paediatricians nationally.

\section{AIMS}

Our aim was to audit the practice in our Emergency Department in relation to this mandate over the 12 months since its' introduction.

\section{METHODS}

Hospital Electronic databases were used to identify those patients aged 14, 15 and 16 years who accessed review in our ED between 01/01/2017 and 01/01/2018. Their ED records were then reviewed to ascertain if those patients presenting with medical problems were seen by our Paediatric team.

\section{RESULTS}

In our 12 month study period there were 2251 presentations to our ED of patients aged 14, 15 or 16 years. Data was available to us on 2038, 1019 (female), 1019 (male), 679 (14yrs), 678 (15yrs) and 681 (16yrs). All medical patients were seen by our Paediatric team.

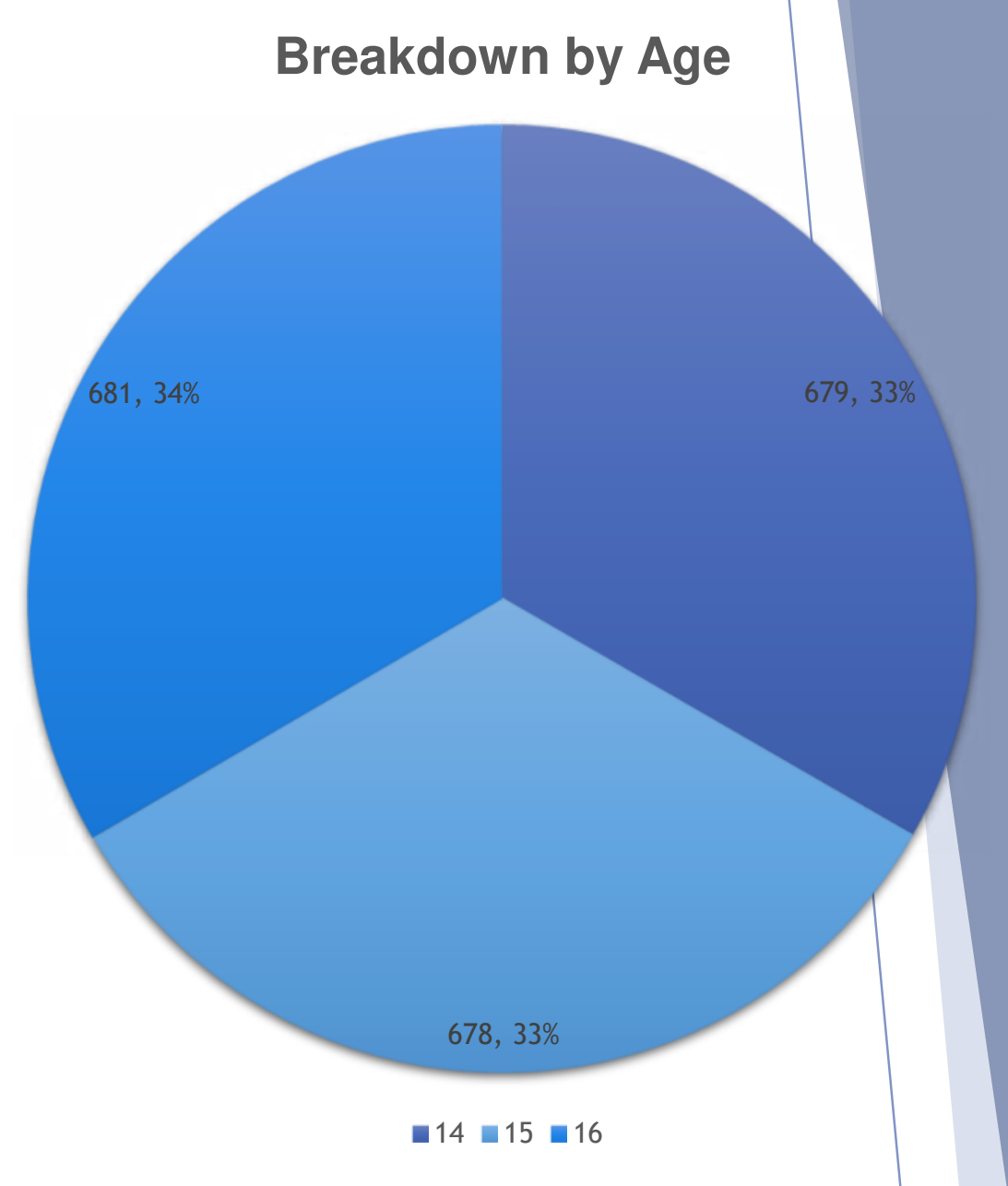

\section{CONCLUSION}

In our unit, the recent National Mandate regarding the medical care of Adolescents aged between 14 and 16 years, presenting to ED by Paediatricians is successfully followed in all cases at this point.

\section{SOURCES}

Li Z, Li M, Patton GC, Lu C. Global Development Assistance for Adolescent Health From 2003 to 2015. JAMA Network Open. 2018;1(4):e181072. doi:10.1001/jamanetworkopen.2018.107

HSE. $(2018,10,15)$. Model of Care for Paediatric Health Care. Retrieved from Healthcare Executive Service: https://www.hse.ie/eng/services/publications/clinical-strategr and-programmes/model-of-care-for-paediatric-healthcareexecutive-summary.pdf 